\title{
市販ケミカルインジケーターによる 薬液の高圧蒸気隇菌の効果の確認*1
}

\author{
鈴木一市, 西川三喜男, 森田久代, 川影逸郎, 藤井喜一郎 \\ 浜松医科大学医学部附属病院薬凨部*2

\section{Confirmation of Sterilization of Pharmaceutical Solutions with Chemical Indicators*1}

\author{
KaZUichi SUzUKI, Mikio Nishikawa, Hisayo Morita, \\ ITURO KAWAKAGE and KIICHIRO FUJII \\ Pharmacy of Hamamatsu University School of Medicine Hospital*2
}

(Received March 4, 1985)

\begin{abstract}
In order to investigate the importance of chemical indicators (CI) in the confirmation of the reliability of sterilization process for pharmaceutical solutions which have different heat penetrations depending upon the container sizes or autoclaves, containers in 3 different capacities $\left(0.5,1,3\right.$ liters) filled with purified water were autoclaved at $115^{\circ}$ for 10 to 60 minutes. In the containers commercial CI's (products A, B and C) were immersed. Sensuous decision, color difference $(\triangle \mathrm{E})$ and LIF, which was found in our previous paper to be useful for the determination of sterilization time in large volume solutions, were evaluated.

Autoclaving time at which $\mathrm{CI}$ gives the confirmation evidence by sensuous decision was shortest when measured in chamber and the time required for products $\mathrm{A}$ and $\mathrm{B}$ was 15 minutes. Autoclaving time in solution was different among the products in the following order: $C>A>B$. But in all products the larger the capacity of containers becomes, the longer the time becomes. Linear relationship between $\Delta \mathrm{E}$ of product $\mathrm{A}$ and of $\mathrm{B}$ and $\log$ of LIF was observed, even if the container size or autoclaving time is different.

LIF, therefore, can be estimated from $\triangle \mathrm{E}$. It is proved that when product $\mathrm{A}$ or $\mathrm{B}$ gives the confirmation evidence for sterilization to solution by sensuous decision, its solution was autoclaved at more than 7 or 6 of LIF, respectively.

Though products A and B should be used for sterilization of materials such as surgical instruments by saturated steam, it was found that when the method to immerse CI in a filling solution was chosen, the use of these CI's in addition to the thermometer gives greater validity to verifying sterility of parenteral solution in hospital pharmacy.
\end{abstract}

Keywords_large volume parenterals; autoclaving; chemical indicator; reliability of sterilization process; color difference-inactivation factor relationship

\section{は じめに}

大容量の薬液を高圧蒸気隇菌する場合に, 隇菌機の缶 体内と薬液の内部とには設定温度への到達時間にずれが

*1 本報を「病院薬局における隇菌工程の管理」第 2 報とする。

*2 浜松市半田町 $3600 ； 3600$, Handa-cho, Hamamatsu-shi, 431-31 Japan
あるため薬液の容量毎に隇菌時間を適宜設定しなければ

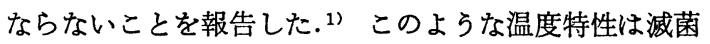
機により異なるため, 薬液や缶体内の熱分布あるいは到 達時間などの熱伝導性を個々の装置について調査する必 要がある. 2 4) しかし, 病院薬局では温度センサーの取 付けなどの問題で, すべての隇菌機にこれらを実施する ことが困難なため，より簡便な方法が望まれる。 蒸気隇菌の効果の確認にヶミカルインジケーター（以 


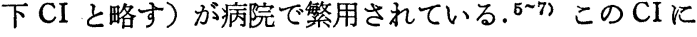
は医療器材などの物品を蒸気隇菌する時に用い, 飽和蒸 気中の物理化学的変化から確認するもの(以下物品用 CI と称す）と容器中に密封された薬液自体の隇菌効果を確 認するために CI を液体中で变化させ，熱源である高圧 蒸気隇菌機により隇菌する時に用いる薬液用のもの（以 下薬液用 CI と称す) がある. 物品用 CI は多数市販さ れているが薬液用 CI はあまり市販されていない。

そこで，薬液用 CI のみでなく物品用 CI を薬夜用と して用いた時の薬液の容量や, 滅菌時間と CI の変色度 合の関係について調査し, 薬液の隇菌効果の確認, さら そ滅菌条件の設定にどの程度利用できるか検討したので 報告する。

\section{実 験 の 部}

\section{1. 実験材料}

容器: $500 \mathrm{ml}, 3 \ell$ (ギャマン製), $1 \ell$ (大河内硝子 製), 薬液: 精製水, CI : Table 1 亿示す 3 種類の製品 （A，B拉よびC）を使用した。製品 $\mathrm{A}$ は物品用 CI で あり, 製品 C は薬液用 $\mathrm{CI}$ である. 製品 $\mathrm{B}$ は薬液用とし て市販されているが，容器の表面に貼布することにより 内部の薬液の熱伝導を反映させて薬液の隇菌効果を確認 するものであり, 容器中の薬液を直接確認しないため, ここでは物品用 CI の範ちゅらに入れる.

\section{2. 装置および温度の測定}

サクラ薬液隇菌装置 FYA-SLJP 200 (サクラ精機) を 用いた. 容器内の温度は, Fig. 1飞示すように温度セン サー（クロメル・アルメル熱電対）をバイアルに挿入し 電子記録計（千野製作所, EM800，6 点式）で記録（チ ヤートスピード： $4 \mathrm{~mm} / \mathrm{min}$ ) して測定した. 温度セン サーの先端は液の高さの中間にした。

また，検討した滅菌機の処理時間は缶体内の温度が設

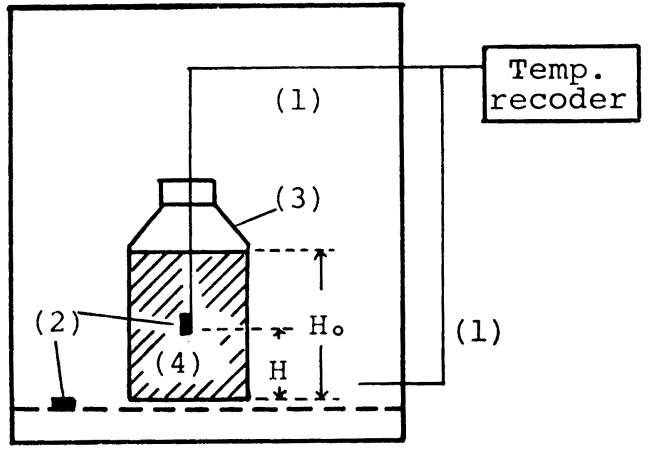

Autoclave chamber

Fig. 1. Diagram of Apparatus for Measurement of Temperature and Change of Chemical Indicator in Container by Autoclave

(1) : Thermocouple

(2) : Chemical indicator

(3) : Glass bottle $\mathrm{H} / \mathrm{H}_{0}=0.5$

(4) : Purified water

定温度に達してから起算する機構のタイマーで変化させ た.この時間をオートクレーブ処理時間とする.

\section{C I の使用法}

隇菌工程中の CI への温度の負荷を薬液の温度变化と 同時に測定するため CI を温度センサーの先端に 固定 し，バイアルに捙入して薬液用 CI とした場合と缶体内 の棚に静置して物品用 $\mathrm{CI}$ とした場合について， $115^{\circ} \mathrm{C}$ で10-60分間オートクレーブ処理した. 1 回の隇菌操作 に打ける被隇菌物の本数は各容量の薬液について 1 本と した．各条件で 3 回オートクレーブ処理しロットによる 変動を求めた.

\section{C I の判定}

肉眼判定 : 各 CI の判定法に準じて薬䩹師 3 名がそれ

Table 1. Chemical Indicator Used in This Study

\begin{tabular}{|c|c|c|c|c|}
\hline Product & Trade name & Manufacturer & Use & $\begin{array}{l}\text { Decision of } \\
\text { sterilization }\end{array}$ \\
\hline A & OK & $\begin{array}{l}\text { Proper MFG.Co., } \\
\text { Inc. }\end{array}$ & Medical material & White $>$ Black \\
\hline B & $\begin{array}{cl}\text { Nesukosu } & \text { I.C } \\
\text { label } & \mathrm{S}\end{array}$ & $\begin{array}{l}\text { Sakura kurepasu } \\
\text { Co. }\end{array}$ & $\begin{array}{l}\text { Pharmaceutical } \\
\text { solution }\end{array}$ & Red $>$ Green \\
\hline c & Temp tube & $\begin{array}{l}\text { Proper MFG.Co., } \\
\text { Inc. }\end{array}$ & $\begin{array}{l}\text { Pharmaceutical } 2 \text { ) } \\
\text { solution }\end{array}$ & Complete fuse \\
\hline
\end{tabular}


ぞれ適・不適を判定した．３名の判定が一致した場合を その試料の適あるいは不適とし，1名でも不一致の場合 は判定保留とした。

変色度合の測定 : カード状あるいはラベル状の製品 $\mathrm{A}$ と Bは，測色色差計（日本電色工業製 N D-100D P) の 固体表面用（6 mm $\phi$ の投光パイプおよび試料台）を用 いて L, a, b を 2 回測定し, 隇菌前の CI に対する色 差 $(\Delta \mathrm{E})$ を式 $(1)$ より求め変色度合とした.

$$
\Delta \mathrm{E}=\sqrt{\left(\mathrm{L}-\mathrm{L}^{\prime}\right)^{2}+\left(\mathrm{a}-\mathrm{a}^{\prime}\right)^{2}+\left(\mathrm{b}-\mathrm{b}^{\prime}\right)^{2}}
$$

ここで L, a , b は滅菌前のCI の色を， $L^{\prime} ， a^{\prime}, b^{\prime}$ は 滅菌後の CI の色を表わす.

製品 Bは変色部分が帯状のためつなぎ合わせて測定し た. 製品Cはガラス管に封入した薬品の熔融状態を判定 する CI のため $\Delta \mathrm{E}$ の判定は行わなかった.

\section{LIF の算出}

前報 ${ }^{1)}$ と同様に隇菌工程中の Log of Inactivation Factor (LIF) を求めた. 今回はチャート紙の眓解法に よる昇温, 排気, 冷却工程のそれぞれ $\mathrm{LIF}_{(\mathrm{h})}, \mathrm{LIF}(\mathrm{ex})$, $\mathrm{LIF}_{(\mathrm{c})}$ は 2.5 分間毎の小部分に区分して求めた.

\section{結果および考莱}

\section{1. オートクレープ処理時間と CI の变色}

i . 肉眼による判定

缶体内, $500 \mathrm{ml}, 1$ およ゙ $3 \ell$ の容器内の各オートク
レーブ処理時間における CI の判定結果を Table 2 に 示す. どの CI も適になる処理時間は, 缶体内が最も短 かく容量が大きくなるにつれて長く, 容器内への熱の伝 導性に影響されている，3ロットとも適になる処理時間 は，缶体内では製品 $\mathrm{A}-15$ 分，製品 $\mathrm{B}-15$ 分および製品 C- 25 分, $500 \mathrm{ml}$ では順に30分，20分および60分以上， 1 lでは30分，30分および60分以上， 3 〕では50分，40分 および60分以上である. 製品間では $\mathrm{B}<\mathrm{A}<\mathrm{C}$ の順に適 の判定に長時間を要している.

薬局方では「減菌されるもののすべての部分が規定の 温度に達してから隇菌時間を起算する」となっているこ とから, 本装置においてはタイマーの作動機構上缶体内 すなわち缶体内に直接置いた CI のオートクレーブ処理 時間が薬局方の滅菌時間に相当することになる，したが って，缶体内の CI の判定から製品 A と B は薬局方の条 件より15分ほどゆるくしても適と判定する危険性があ る.しかし，この結果は薬液用 CI があまりない現状で は, 肉眼判定で不適となればその薬液は隇菌不十分であ るといえることや，市販されている CI の信頼性が必ず しも確立していないこと到から，これら物品用 CI を薬 液用に利用できることを示している．製品 $\mathrm{C}$ は $121^{\circ} \mathrm{C}$ 以

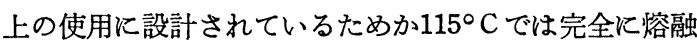
しないことがあり判定しにくい.

ii . $\Delta \mathrm{E}$ による変色度合の評価

製品 $\mathrm{A}$ および $\mathrm{B}$ は色差計を用いて変色度合の数值化を

Table 2. Sensuous Decision of Chemical Indicator and Autoclaving Time in the Various Containers (Suitable number/The number of autoclaving)

\begin{tabular}{|c|c|c|c|c|c|c|c|c|c|c|c|}
\hline \multirow{2}{*}{ Product } & \multirow{2}{*}{$\begin{array}{c}\text { Volume } \\
\text { (m1) }\end{array}$} & \multicolumn{5}{|c|}{ autoclaving } & time & \multicolumn{4}{|l|}{ (min) } \\
\hline & & 10 & & 15 & 20 & 25 & 30 & 40 & 50 & 60 & \\
\hline \multirow{4}{*}{ A } & 3000 & $0 / 3$ & & $0 / 3$ & $0 / 3$ & $0 / 3$ & $0 / 3$ & $2 / 3$ & $3 / 3$ & $3 / 3$ & ] \\
\hline & 1000 & $0 / 3$ & & $0 / 3$ & $0 / 3$ & $1 / 3$ & $3 / 3$ & $3 / 3$ & $3 / 3$ & $1 / 1$ & ] \\
\hline & 500 & $0 / 3$ & & $0 / 3$ & $(1) / 3$ & $(2) / 3$ & $3 / 3$ & $3 / 3$ & $3 / 3$ & - & ] \\
\hline & Chamber & $2 / 3$ & [ & $3 / 3$ & $2 / 2$ & $2 / 2$ & $3 / 3$ & $2 / 2$ & $3 / 3$ & - & ] \\
\hline \multirow{4}{*}{ B } & 3000 & $0 / 3$ & & $0 / 3$ & $0 / 3$ & \multirow{2}{*}{$\begin{array}{r}(1) / 3 \\
2(1) / 3\end{array}$} & $(3) / 3$ & \multirow{4}{*}{$\begin{array}{l}3 / 3 \\
3 / 3 \\
3 / 3 \\
3 / 3\end{array}$} & $3 / 3$ & $2 / 2$ & ] \\
\hline & 1000 & $0 / 3$ & & 1) $/ 3$ & $(3) / 3$ & & $3 / 3$ & & $3 / 3$ & $2 / 2$ & ] \\
\hline & 500 & $0 / 3$ & & 1) $/ 3$ & $3 / 3$ & $3 / 3$ & $3 / 3$ & & $3 / 3$ & $2 / 2$ & ] \\
\hline & Chamber & $2(1) / 3$ & [ & $3 / 3$ & $3 / 3$ & $3 / 3$ & $3 / 3$ & & $2 / 2$ & $1 / 1$ & ] \\
\hline \multirow{4}{*}{$\mathrm{C}$} & 3000 & $0 / 1$ & & $0 / 1$ & $0 / 1$ & - & $0 / 2$ & - & $0 / 1$ & \multicolumn{2}{|l|}{$0 / 2$} \\
\hline & 1000 & $0 / 1$ & & $0 / 1$ & $0 / 1$ & $0 / 1$ & $0 / 4$ & $0 / 3$ & $1(2) / 3$ & \multicolumn{2}{|l|}{$2(1) / 3$} \\
\hline & 500 & $0 / 1$ & & $0 / 1$ & $0 / 1$ & $0 / 1$ & $(2) / 4$ & $(3) / 3$ & $2(1) / 3$ & - & \\
\hline & Chamber & $0 / 1$ & & - & $0 / 1$ & $1 / 1$ & $3 / 3$ & $3 / 3$ & - & - & ] \\
\hline
\end{tabular}

( ) : The number of autoclaving reserved the decision

[ ] : The suitability in all of three autoclavings 
Table 3. Color Difference $(\Delta \mathrm{E})$ of Chemical Indicator and Autoclaving Time in the Various Containers

\begin{tabular}{|c|c|c|c|c|c|c|c|c|c|}
\hline \multirow[b]{2}{*}{ Product } & \multirow[b]{2}{*}{$\begin{array}{l}\text { Volume } \\
(\mathrm{m} 1)\end{array}$} & \multicolumn{8}{|c|}{ autoclaving time $(\min )$} \\
\hline & & 10 & 15 & 20 & 25 & 30 & 40 & 50 & 60 \\
\hline \multirow{4}{*}{ A } & 3000 & $9.7 \pm 4.1$ & $17.2 \pm 7.6$ & $21.5 \pm 8.1$ & $35.5 \pm 6.5$ & $46.0 \pm 3.4$ & $51.5 \pm 4.1$ & {$[54.8 \pm 2.0$} & $57.0 \pm 1.7]$ \\
\hline & 1000 & $27.9 \pm 1.9$ & $36.9 \pm 3.0$ & $43.9 \pm 2.5$ & $50.5 \pm 3.4$ & {$[52.8 \pm 0.4$} & $56.3 \pm 0.5$ & $57.0 \pm 0.4$ & $57.5 \pm 0.4]$ \\
\hline & 500 & $37.9 \pm 5.0$ & $46.8 \pm 1.3$ & $49.0 \pm 1.2$ & $51.7 \pm 1.1$ & {$[55.2 \pm 0.2$} & $56.3 \pm 0.9$ & $57.7 \pm 0.5$ & - \\
\hline & Chamber & $56.8 \pm 1.3$ & {$[57.5 \pm 4.2$} & $56.9 \pm 4.0$ & $59.5 \pm 0.9$ & $59.4 \pm 0.6$ & $58.8 \pm 2.1$ & $59.6 \pm 1.3$ & - \\
\hline \multirow{4}{*}{ B } & 3000 & $18.9 \pm 1.6$ & $28.9 \pm 2.3$ & $37.9 \pm 1.9$ & $45.0 \pm 1.2$ & $49.6 \pm 1.6$ & {$[55.5 \pm 0.5$} & $56.4 \pm 1.2$ & $57.5 \pm 0.1]$ \\
\hline & 1000 & $36.8 \pm 2.8$ & $45.2 \pm 1.2$ & $50.0 \pm 1.8$ & $54.3 \pm 1.4$ & {$[54.7 \pm 1]$.} & $55.8 \pm 0.2$ & $57.4 \pm 0.4$ & $57.1 \pm 1.3]$ \\
\hline & 500 & $43.4 \pm 3.7$ & $50.8 \pm 0.5$ & {$[52.7 \pm 2.1$} & $55.6 \pm 0.9$ & $53.3 \pm 2.7$ & $57.5 \pm 1.4$ & $56.7 \pm 0.8$ & - \\
\hline & Chamber & $50.1 \pm 2.6$ & {$[54.6 \pm] .2$} & $56.5 \pm 0.6$ & $56.1 \pm 1.0$ & $56.9 \pm 0.8$ & $56.0 \pm 0.8$ & - & $57.9 \pm 2.8]$ \\
\hline
\end{tabular}

Each value represent the mean $\pm S . D \quad(n=3)$

[ ] : The suitability in all of three autoclavings

Table 4. Log of Inactivation Factor (LIF) and Autoclaving Time in the Various Containers

\begin{tabular}{|c|c|c|c|c|c|c|c|c|}
\hline \multirow{2}{*}{$\begin{array}{l}\text { Volume } \\
\text { ( ml ) }\end{array}$} & \multicolumn{4}{|c|}{ autoclaving } & time & \multicolumn{2}{|l|}{$(\min )$} & \multirow[b]{2}{*}{60} \\
\hline & 10 & 15 & 20 & 25 & 30 & 40 & 50 & \\
\hline 3000 & $\begin{array}{l}0.06 \\
\quad \pm 0.02\end{array}$ & $\begin{array}{l}0.22 \\
\pm 0.02\end{array}$ & $\begin{array}{l}0.50 \\
\quad \pm 0.12\end{array}$ & $\begin{array}{l}1.12 \\
\pm 0.26\end{array}$ & $\begin{array}{l}2.22 \\
\quad \pm 0.35\end{array}$ & $\begin{array}{l}4.44 \\
\quad \pm 0.85\end{array}$ & $\begin{array}{l}6.61 \\
\quad \pm 1.00\end{array}$ & $\begin{array}{l}10.7 \\
\pm 0.7\end{array}$ \\
\hline 1000 & $\begin{array}{l}0.85 \\
\quad \pm 0.57\end{array}$ & $\begin{array}{l}1.71 \\
\quad \pm 0.47\end{array}$ & $\begin{array}{l}2.95 \\
\quad \pm 0.32\end{array}$ & $\begin{array}{l}4.40 \\
\quad \pm 0.36\end{array}$ & $\begin{array}{l}6.21 \\
\pm 0.31\end{array}$ & $\begin{array}{l}8.75 \\
\pm 0.33\end{array}$ & $\begin{array}{l}11.5 \\
\pm 0.6\end{array}$ & $\begin{aligned} 12.9 & \\
& \pm 1.9\end{aligned}$ \\
\hline 500 & $\begin{array}{l}1.67 \\
\pm 0.32\end{array}$ & $\begin{array}{l}3.22 \\
\quad \pm 0.32\end{array}$ & $\begin{array}{l}4.66 \\
\pm 0.41\end{array}$ & $\begin{array}{l}5.95 \\
\quad \pm 0.23\end{array}$ & $\begin{array}{r}7.37 \\
\pm 0.54\end{array}$ & $\begin{array}{l}10.6 \\
\pm 0.5\end{array}$ & $\begin{array}{l}13.0 \\
\pm 0.3\end{array}$ & - \\
\hline Chamber & $\begin{array}{l}3.64 \\
\quad \pm 0.11\end{array}$ & $\begin{array}{l}5.34 \\
\quad \pm 0.27\end{array}$ & $\begin{array}{l}6.52 \\
\quad \pm 0.07\end{array}$ & $\begin{array}{l}7.77 \\
\quad \pm 0.10\end{array}$ & $\begin{array}{l}9.53 \\
\pm 0.16\end{array}$ & $\begin{aligned} & 12.5 \\
& \pm 0.1\end{aligned}$ & $\begin{array}{l}15.1 \\
\pm 0.1\end{array}$ & - \\
\hline
\end{tabular}

Each value represent

試みた。同一試料の測定場所による $\Delta \mathrm{E}$ のばらつきは， 0.2〜0.6であった. $\Delta \mathrm{E}$ の結果を Table 3 亿示す. ロッ 卜間のばらつきは， $\Delta \mathrm{E}$ が小さい時すなわち減菌効果が 不十分な時隹められているが，処理時間を長くした り, 容器の容量が小さくなると $\Delta \mathrm{E}$ は有意に上昇し, 隇 菌条件の相異による变色度合を客観的かつ詳細に評価で きる. Table 2 の肉眼判定の結果と対比すると適・不適 の判定の境界は製品 $\mathrm{A}, \mathrm{B}$ とも $\Delta \mathrm{E}$ が53付近にある. 製 品 $\mathrm{A}$ の缶体内の場合は, 薬液中に侵漬した場合と色調が 異なり $\Delta \mathrm{E}$ と肉眼判定とが一致しないため注意する必要 the mean $\pm S . D \quad(n=6)$

がある。

2. オートクレーブ処理時間と LIF のばらつき

各条件に批る LIF とそのばらつきを Table 4 に示 す. LIF のばらつきは缶体内と容器の内部の設定温度に

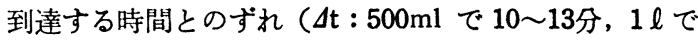
16〜20分, $3 \ell$ で36〜42分)1) より短かいオートクレーブ 処理時間の場合に大きい，この原因は $\Delta \mathrm{t}$ 以下の処理時 間では $\mathrm{LIF}=\mathrm{LIF}_{(\mathrm{h})}+\mathrm{LIF}_{(\mathrm{s})}+\mathrm{LIF}_{(e x)}+\mathrm{LIF}_{(\mathrm{c})}$ Kおいて $\mathrm{LIF}_{(s)}=0$ となり显温, 排父扰よび冷却工程だけの LIF のためこの工程の容器内への熱伝導がロットによって異 


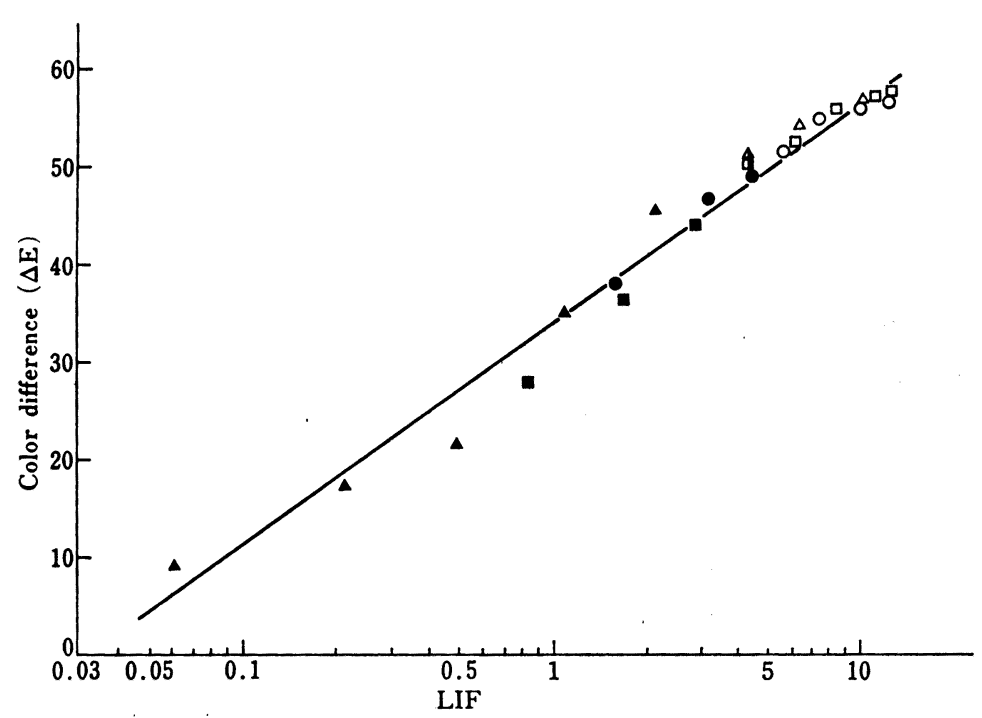

Fig. 2. Relationship between $\Delta \mathrm{E}$ of Product $\mathrm{A}$ and LIF in the Various Containers by Autoclaving

$$
\triangle: 3000 \mathrm{ml} \square: 1000 \mathrm{ml} \bigcirc: 500 \mathrm{ml}
$$

Open plot represents the suitability in all of three autoclavings by sensuous decision.

Semi-open plot represents the unsuitability in at least one autoclaving. Closed plot represents the unsuitability in all of three autoclavings.

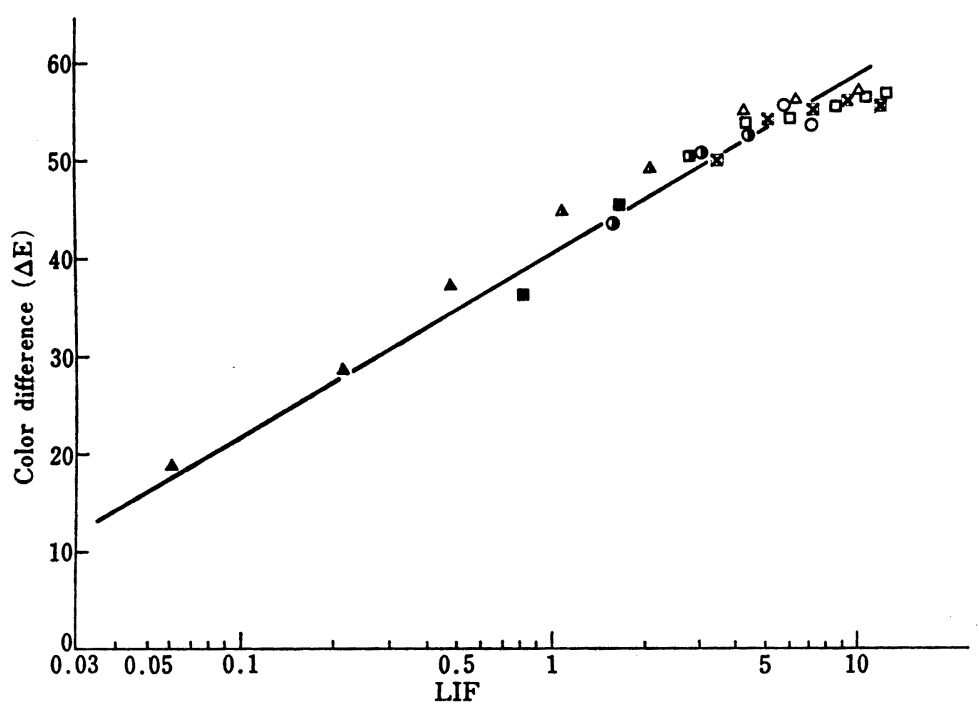

Fig. 3. Relationship between $\Delta \mathrm{E}$ of Product $\mathrm{B}$ and LIF in the Various Containers by Autoclaving

$$
\triangle: 3000 \mathrm{ml} \square: 1000 \mathrm{ml} \bigcirc: 500 \mathrm{ml} \times: \text { chamber }
$$

Open plot represents the suitability in all of three autoclavings by sensuous decision.

Semi-open plot represents the unsuitability in at least one autoclaving. Closed plot represents the unsuitability in all of three autoclavings. 
なるためと考えられる.

\section{CI の $\Delta \mathrm{E}$ と LIF の関係}

CI の変色度合は設定温度における熱エネルギーだけ でなく，滅菌工程中に負荷される全熱エネルギーに左右 されると考えられる．LIFは滅菌の全工程における細菌 の不活化の程度を速度論的に取扱ったもので滅菌中の全 熱エネルギーの指標と考えてもよい.この LIF と CI の $\Delta \mathrm{E}$ との間に何らかの関係が成立すれば， CI の $\Delta \mathrm{E}$ から 隇菌した薬液の LIF を予測でき, 隇菌効果の確認を行え る. そこで， $\Delta \mathrm{E}$ に対する LIF の対数值をプロットした 結果，製品 A 扣よびBはそれぞれ Fig. 2，3 のように相 関係数が $0.973(\mathrm{p}<0.01)$ と $0.962(\mathrm{p}<0.01)$ となり $\Delta \mathrm{E}$ と LIF の対数值に良好な直線関係が成立した. 最小 二乗法で求めた製品 $\mathrm{A}$ 打よび $\mathrm{B}$ の回帰式は，それぞれ (2)，(3)式で表わすことができた.

$$
\begin{aligned}
& \Delta \mathrm{E}=33.7+23.1 \log \mathrm{LIF} \\
& \Delta \mathrm{E}=41.2+16.6 \log \mathrm{LIF}
\end{aligned}
$$

なお，製品 $\mathrm{A}$ の缶体内の $\mathrm{CI}$ は色調や容器内の $\mathrm{CI}$ の $\Delta \mathrm{E}$ とLIF の関係から著しくはずれたので回㷌分析から 除外した．したがって，温度センサーで熱伝導性を調査 しなくても CI の $\Delta \mathrm{E}$ を測定すればどんな容量の薬液で も滅菌工程中の LIF を予測できることがわかった．さ らに肉眼判定の結果を LIF と対比すると, 製品Aでは 3 ロットとも不適と判定した LIF は 4 以下，少なくと も1ロットは不適とした LIF は 4〜6，3ロットとも 適とした LIF は 7 以上であり, 製品 Bでは順に 1 以下, $1 \sim 5$ および 6 以上となっている。このことから，たと え LIF と $\Delta \mathrm{E}$ の両方を測定できなくても，隇菌効果を 肉眼的に確認できるし，条件設定の目安として利用する ことも可能になる. 薬局方の $115^{\circ} \mathrm{C}, 30$ 分の LIF は8.7 で，しかもこの值は LIF $(\mathrm{s}$, だけで他の工程の LIF を含 まないことやCI の適と判定する LIF が 8.7 より小さい ことなどから条件設定に際しては，CI で適となる条件
よりもオートクレーブ処理時間を長くする必要がある.

物品用 CI である製品 $\mathrm{A}$ およびBを薬夜用として用い たためCI の精度を論ずることはできないが，これら CI は薬夜にも十分使用できるため薬局方の隇菌条件に一致 する薬液専用の CI が開発されればその精度も高まり， 薬液の隇菌工程の管理に有用となる。

\section{結}

物品用 CI の製品 $\mathrm{A}$ および $\mathrm{B}$ は, 薬局方の隇菌条件に 一致するよう改良すれば，ハイイアルの精製水中に浸漬し て内容薬液の隇菌効果を確認するための薬液用 $\mathrm{CI}$ とし て利用できることがわかった。

$\mathrm{CI}$ の变色度合を $\Delta \mathrm{E} て ゙$ 評価すると, 容器の容量に関係 なく $\Delta \mathrm{E}$ と LIF の対数值に良好な直線性が認められた ので， $\Delta \mathrm{E}$ から各薬液の隇菌工程中の LIF が予測でき， 容器の容量を考虑した隇菌条件の設定を行うことも可能 である.

容器内の温度を測定する機器のある減荣機ばかりでな く, この機器のない隇菌機の薬夜の隇菌工程の管理の一 手段に市販されているCI を用いれば, 病院薬局の無菌 製剤の品質保証をさらに高めることができる.

碀辞 本研究に際しヶミカルインジケーターの試料を 提供していただいたサクラクレパス株式会社，ホギ株式 会社に感謝いたします。

\section{文献}

1）鈴木一市, 石川安信, 川影逸郎, 藤井喜一郎：病 院薬学, 7, 173 (1981)

2）長崎泉吉: 防菌防微，12，279 (1984).

3）塩路雄作：月刊薬事，26，1423 (1984).

4) 田中交彦, 川村邦夫：防菌防徽, 7, T 286 (1979).

5）今城千代子：防菌防微， 7, T 137 (1979).

6) 今城千代子：防菌防敉, 7, T196 (1979).

7）綿貫喆, 実川佐太郎：“隇菌法・消毒法,”（椯原 欣作編）“第 2 集, 交光堂, 東京, 1979 . 